\title{
NO PRIMEIRO ANO DE MANDATO, NÃO SE CUMPREM PROMESSAS
}

Coluna publicada em 20.11.2012: <http://www.conjur.com.br/2012-nov-20/ contas-vista-primeiro-ano-mandato-nao-cumprem-promessas $>$

As eleições acabaram, prefeitos e vereadores estão eleitos, os vencedores festejaram. Daqui a pouco mais de um mês, tomam posse. E começarão a trabalhar. Expectativas, muito justas e até óbvias, se formam em torno dos novos prefeitos e vereadores, que assumem comprometidos a tornar reais todas as promessas feitas poucos meses antes, ao longo da campanha eleitoral.

Sem querer estragar a festa, nem frustrar expectativas, aproveito o momento para algumas considerações em torno do sistema orçamentário brasileiro, que tem algumas peculiaridades sobre as quais é interessante refletir.

A boa gestão da administração pública não pode prescindir de um sistema de planejamento da ação governamental, envolvendo aspectos de longo, médio e curto prazos.

$\mathrm{O}$ aspecto essencial do ordenamento jurídico que cuida do planejamento da ação governamental dos entes federados está previsto no artigo 165 da Constituição Federal, que estrutura o sistema em função de três leis: o plano plurianual (PPA), a lei de diretrizes orçamentárias (LDO) e a lei orçamentária anual (LOA).

O plano plurianual é válido por quatro anos e nele estão contidos as diretrizes, objetivos e metas da administração pública para as despesas de capital e programas de duração continuada. O projeto de lei do PPA deve ser apresentado pelo chefe do Poder Executivo ao Poder Legislativo até quatro meses antes do encerramento do primeiro exercício financeiro, ${ }^{1}$ para, após aprovado, vigorar até o final do primeiro exercício financeiro do mandato subsequente.

$1 \quad \mathrm{Na}$ esfera federal, nos termos do artigo 35, $\$ 2^{\circ}$, I do ADCT-CF. Os prazos podem variar conforme o estado e o município. Em geral, estados e municípios costumam definir, nas 
A lei de diretrizes orçamentárias tem por finalidade estabelecer as metas e prioridades da administração pública para as despesas de capital do exercício financeiro subsequente e orientar a elaboração da lei orçamentária anual, entre outras funções. Trata-se de lei anual, a ter seu projeto encaminhado pelo chefe do Poder Executivo ao Poder Legislativo até oito meses e meio antes de findo o exercício financeiro, ${ }^{2}$ produzindo parte de seus efeitos até a aprovação da lei orçamentária e parte durante o exercício financeiro subsequente, em função de disposições que cuidam da execução da lei orçamentária.

E a lei orçamentária - o orçamento propriamente dito -, que define as receitas e despesas para o exercício financeiro subsequente, tem seu projeto apresentado, todos os anos, pelo chefe do Poder Executivo ao Poder Legislativo até quatro meses antes do encerramento do exercício financeiro. ${ }^{3}$

A análise cuidadosa desses prazos permite constatar algumas questóes interessantes.

Os prefeitos recém-eleitos, por força da legislação eleitoral, tomam posse e iniciam seu mandato no próximo dia $1^{\circ}$ de janeiro. Exatamente na data em que começa a ser executada a lei orçamentária (Lei 4.320/1964, art. 32).

Ocorre que o orçamento a ser executado, como se pode ver, teve seu projeto apresentado pelo prefeito atualmente em exercício e aprovado pela câmara de vereadores dessa legislatura - e não da que vai tomar posse. Mais do que isso. Segue as determinações impostas pela lei de diretrizes orçamentárias aprovada no primeiro semestre do ano em curso. Que, por sua vez, está em consonância com o plano plurianual, ${ }^{4}$ elaborado pelo Poder Executivo e aprovado Legislativo atualmente no exercício do poder.

Em outras palavras, e não há como concluir de outra forma: se observado o ordenamento jurídico, caberá ao prefeito eleito, durante o primeiro ano de mandato, cumprir o que foi estabelecido por seu antecessor!

respectivas Constituições Estaduais e Leis Orgânicas Municipais, esse prazo estendido em um mês, ou seja, até três meses antes do encerramento do primeiro exercício financeiro.

$2 \mathrm{Na}$ esfera federal, nos termos do artigo $35, \$ 2^{\circ}$, II do ADCT-CF. Pode haver pequenas variações de datas nos estados e municípios, conforme estabelecido pelas respectivas Constituições Estaduais e Leis Orgânicas Municipais.

$3 \mathrm{Na}$ esfera federal, nos termos do artigo 35, $\$ 2^{\circ}$, III do ADCT-CF. Pode haver pequenas variações de datas nos estados e municípios, conforme estabelecido pelas respectivas Constituições Estaduais e Leis Orgânicas Municipais.

4 Lei de Responsabilidade Fiscal, artigo $5^{\circ}$. 
O sistema de planejamento da ação governamental está, em linhas gerais, bem construído, e há de ser respeitado, tanto pela óbvia razão de estar fundado em normas constitucionais e legais vigentes, como também por ser coerente com as modernas técnicas de gestão, que exigem uma ação planejada, tanto mais eficientes quanto maior a segurança jurídica que lhes der sustentação.

No entanto, os prazos estabelecidos pela legislação eleitoral provocam esta situação ${ }^{5}$ que pode gerar frustrações, tanto nos recém-eleitos, pelas dificuldades em implementar seus programas, como nos eleitores, ávidos pelo atendimento rápido de suas necessidades e das expectativas depositadas nos novos governantes.

Há meios de contornar, ainda que em parte, esta situação. Toda lei orçamentária é dotada de mecanismos de flexibilidade, permitindo que seja alterada, com a finalidade de adaptar a execução orçamentária às alterações surgidas no decorrer do exercício financeiro, mas sem desviar o curso do que nela foi estabelecido. Para isso, são previstos créditos adicionais, possibilidades de remanejamentos e outros instrumentos. Em prol da segurança jurídica e da boa gestão, no entanto, não se pode usar desses mecanismos para modificar significativamente o conteúdo da lei orçamentária, aprovada de forma legítima nos exatos termos da legislação vigente.

Há que se lembrar ainda de algumas restrições constitucionais importantes, como a vedação do início de programas ou projetos não incluídos na lei orçamentária anual (CF, art. 167, I), bem como a proibição de dar início, sem prévia inclusão no plano plurianual, a investimentos cuja execução ultrapasse um exercício financeiro, o que caracteriza, inclusive, crime de responsabilidade (CF, art. 167, $\$ 1^{\circ}$ ).

Sendo assim, o primeiro ano de mandato não é, em regra, destinado a cumprir as promessas de campanha - ou, pelo menos, boa parte delas -, mas sim dar continuidade aos projetos em andamento e planejar os próximos anos, elaborando o plano plurianual que regerá a administração pública nos quatro anos subsequentes.

De qualquer forma, não é desarrazoado refletir sobre esses fatos, até para sugerir eventuais alteraçooes que possam minimizar esta situação que é, e parte, incoerente, pois obriga o administrador a gerir a máquina pública de forma, muitas vezes, sem sintonia com a vontade popular que, não raro, votou esperando mudança de rumos, que acabará por retardar a acontecer.

Modificações nos prazos dessas leis, sejam elas de natureza eleitoral, alterando a data de eleições e/ou início de mandato, ou ainda nas datas de tramitação das leis orçamentárias, mesmo que apenas em anos eleitorais, são algumas possibilidades.

Prefeito no $1^{\circ}$ ano do mandato cumprir o estabelecido pelo sucessor. 
E aproveitar a oportunidade para ajustar uma antiga distorção ainda em vigor no que tange aos prazos de tramitação das leis de natureza orçamentária. Vejamos.

Há uma coerência no sistema de planejamento da ação governamental, com leis que se coordenam de modo a fazer com que o plano plurianual condicione a elaboração da lei de diretrizes orçamentárias que, por sua vez, delimita os parâmetros a serem seguidos pela lei orçamentária anual. ${ }^{6}$

Observem que a apresentação do projeto de lei do plano plurianual deverá ser feita pelos próximos prefeitos no final do ano que vem (2013), para vigorar a partir do início do exercício subsequente (2014). No entanto, a lei de diretrizes orçamentárias, que deverá guardar coerência com o plano plurianual, será elaborada no primeiro semestre do ano que vem (2013), condicionando a elaboração da lei orçamentária anual, a ser aprovada no final de 2013 para vigorar em 2014, e contendo dispositivos capazes de regular a execução orçamentária, que ocorrerá ao longo de 2014. Dessa forma, no exercício de 2013, a LDO será elaborada antes do plano plurianual; e a lei orçamentária, concomitantemente ao plano plurianual; e todas produzirão efeitos em 2014, tornando, evidentemente, inviável a perfeita coerência entre elas. Há que se pensar em uma solução legislativa para resolver essa distorção.

E lanço uma sugestão sobre outra questão, para refletir. É fato ser o plano plurianual uma lei complexa, que exige o conhecimento da máquina administrativa para ser elaborada de forma precisa e adequada. No entanto, representa verdadeiro plano de governo, em que se expóem, de forma concreta, os programas e ações governamentais que se pretendem implantar e desenvolver durante o mandato. Não seria descabido exigir dos candidatos, por ocasião do registro das respectivas candidaturas, ainda que em versão simplificada, um esboço do plano plurianual que pretende apresentar no início de seu mandato. Permitiria a seus eleitores votar de forma mais consciente, escolhendo aquele que, além de demonstrar seriedade, comprometimento e conhecimento dos problemas que pretende administrar, evidencia ter em mente as soluçôes concretas que pretende aplicar.

Aos legisladores, concito-os a pensar sobre os assuntos levantados.

Aos prefeitos, desejo-lhes boa sorte em seus mandatos.

$\mathrm{E}$ aos eleitores, que tenham um pouco de paciência...

6 Como já escrevi em: CONTI, José Mauricio. Planejamento e responsabilidade fiscal. In: SCAFF, Fernando F.; CONTI, José Mauricio. Lei de responsabilidade fiscal. 10 anos de vigência - questões atuais. Florianópolis: Conceito Editorial/IBDF, 2010, p. 51. 